\title{
El ámbito modernista de Melilla
}

\begin{abstract}
"No por sorprendente ha de resultar menos grato -sino todo lo contrario- el considerar a Melilla, de una vez por todas, como ciudad-museo del eclecticismo, muy especialmente de la arquitectura modernista..."
\end{abstract}

Luciano Tejedor

Laura Cantón Fernández y Ana Riaño López

En torno al panorama artístico europeo

La última mitad del siglo XIX representa una de las etapas más confusas y problemáticas de la historia de la arquitectura europea. En ella confluyen diversas tendencias que responden a términos de muy dilatado ámbito conceptual; como son neomedievalismo, eclecticismo y modernismo, cada uno con sus respectivas variantes.

Llegado a su término el neoclasicismo, a partir de 1850 el panorama artístico europeo ofrece como posibles alternativas a la mayoría de los arquitectos no sólo el estilo gótico y el clásico, sino también el románico, el bizantino, el egipcio, el árabe, el renacentista, etc.

De esta forma se entiende y extiende esa actitud denominada "eclecticismo", que implicaba una sucesión de estilos igualmente válidos, pero heterogéneos en sus fórmulas, más o menos antagónicos entre sí, y cuya práctica creaba graves discontinuidades en la producción de un arquitecto.

Es claro que el eclecticismo se manifiesta entre el neomedievalismo o historicismo y el modernismo, actitudes éstas que se superponen sin tratar de ser tres momentos cronológicamente consecutivos. Por tanto, eclecticismo e historicismo son tendencias paralelas. Del modernismo hablaremos más adelante.

Reiteradas veces la arquitectura de carácter historicista recibe el apela- 
tivo de ecléctica o viceversa, apareciendo unidas (1). Sin embargo, existen diferencias entre uno y otro. El eclecticismo, tratado la mayoría de las veces injustamente, con un sentido peyorativo, aparece como un fenómeno heterodoxo, carácter éste que le confiere independencia frente a aquéllos que siguieron los modelos históricos o contemporáneos (2).

"En este sentido podemos considerar el eclecticismo no como una etapa de impotencia proyectual, sino como una nueva alternativa, como un método consciente y reflexivo para superar el problema de los historicismos" (3).

En Espafia esta tendencia a la que nos venimos refiriendo fue aceptada por unos como una solución de tránsito, y por otros, como Luis Domenech y Montaner, como una actitud en la que se deben apreciar valores muy positivos.

Defendido por unos, criticado por otros, algunos de estós últimos se dan perfecta cuenta de que ante tales contradiciones era necesario "llevar el razonamiento más allá de las apariencias formales, y basar las opciones en razones objetivas, demostrables racionalmente" (4).

Surge así, en Europa, el racionalismo decimonónico, teor fa ésta que tampoco en la praxis serfa capaz de prescindir de estilos pasados, clásicos o medievales.

España, que vive por entonces la restauraci ón alfonsina, recibe de Europa el neocatolicismo postconciliar (Vaticano I) dando un sentido peculiar a la arquitectura neomedieval en base a que el estilo medieval era el más apto. En tal conyuntura se apuntaban dos caminos: "o se volv ra a las recreaciones historicistas, o bien, tomando la historia como punto de partida, se intentaba algo inédito a través de una revisión razonada desde la óptica moderna. Esta segunda posibilidad era la más arriesgada $y$, por lo tanto, la que menos frutos dio" (5). Nos estamos refiriendo al racionalismo neogótico que influenciado por las ideas de Viollet-le Duc llegó a nosotros a través de Juan de Madrazo.

En la segunda mitad del siglo XIX, ante el progreso industrial, la técnica de la construcción y el aprovechamiento de nuevos materiales, como el hierro, se perfeccionan vertiginosamente.

Para España hacen proyectos Horeau y Eiffel. A este momento pertenecen la mayoría de las estaciones de ferrocarril, los mercados, edificios

(1) FUSCO DE, Renato: Historia de la Arquitectura Contemporánea. Biblioteca Básica de Arquitectura. H. Blume Ediciones, Madrid, 1975.

(2) NAVASCUES, P.; PEREZ, C.; ARIAS DE COSSIO, Ana M. ${ }^{a}$ : Historia del Arte Hispánico. Vol. del necoclasicismo al modernismo. Ed. Alhambra, Madrid, 1979.

(3) CAMACHO MARTINEZ, Rosario: "El eclecticismo en la arquitectura religiosa de Melilla", en Boletín de Arte núm. 2, 1981, Universidad de Malaga. Dpto. de Historia del Arte.

(4) BENEVOLO, Leonardo: Historia de la arquitectura moderna. Editorial Gustavo Gili, Barcelona, 1979, pág. 130.

(5) NAVASCUES y otros, obra citada, pág. 74. 
para espectáculos públicos, teatros, circos y pabellones de exposición. Todo conducía inevitablemente hacia una etapa de la arquitectura en la que el hierro se destacaría de los otros materiales constructivos, produciéndose la transformación, en definitiva, la modernización del paisaje urbano.

Esta situación inquietó a personajes como Rada y Delgado que en 1882 escrib ra: "la industria matará al arte" (6).

En medio de este proceso de modernización, el eclecticismo entra en crisis, aunque necesario aclarar que historicismo y ecleticismo prolongaron su agonfa hasta bien entrado el siglo XX.

Los artistas de la vanguardia europea, siguiendo los principios de Julien Gaudent (1834-1908), profesor de teoría de la arquitectura de la Academia, crean un nuevo lenguaje que proclama la libertad individual y la fantas fa, un nuevo arte independiente de los estilos tradicionales.

\section{Principales aspectos del modernismo}

En las ulltimas décadas del siglo XIX nace el Art Nouveau o modernismo, estilo que, en su significado más amplio, incluye a todos los movimientos de vanguardia europeos que se conocen con términos análogos (Jugendstil, Moderns Style, Liberty, Sezession, etc.), y que alcanzará su plenitud en los albores de nuestro siglo.

Este modernismo arquitectónico va a combatir el eclecticismo de los "estilos modemos" por lo que conlleva de falso historicismo y por su tendencia a la oficialidad (7).

El modernismo surge por diversas motivaciones. Entre ellas las más destacables fueron la necesidad de reaccionar contra el perdurable academicismo o eclecticismo arquitectónico, al que nos acabamos de referir, y el deseo de creación de un estilo original que respondiese a las inquietudes suscitadas por el imperialismo de la industrialización. Y sería Inglaterra el país que más influiría en la aparición de este estilo. Importantes fueron las tesis elaboradas por Willian Morris (1834-1896), fiel seguidor de las teorías reformistas de Ruskin, llamado ápostol de la belleza y el arte (8), quien combatía la fabricación de objetos a máquina no sólo desde un punto de vista estético, sino también del técnico, sosteniendo que la industrialización creaba fealdad y miseria. El repudio de la máquina llegará a convertirse en uno de los más importantes puntos de la filosof áa del Art Nouveau. Los últimos años del siglo XIX y primeros del $\mathrm{XX}$ quedarán marcados por

(6) NAVASCUES y otros, obra citada, pág. 71.

(7) CARLO ARGAN, Giulio: El arte Maderno. Vol. I, Fernando Torres, Editor. Valencia, 4. ${ }^{a}$ ed. 1977 , pág. 232.

(8) LITVAK, Lily: Transformación industrial y literatura en España (1895-1905). Taurus Ediciones, Madrid, 1980, pág. 13. 
una estética que de modo consciente quiso revolucionar las artes, retornando al sistema artesanal que exaltaba los ideales culturales y estéticos, puestos en entredicho por la civilización industrial, considerada alienante y embrutecedora, al mismo tiempo que exal taba también las artesan fas.

Efectivamente, las artes decorativas y aplicadas se convirtieron en el centro de atención del modernismo. Si las artes aplicadas expusieron su sentido artesanal a través de la confección de papeles pintados, muebles $y$, sobre todo, decoración de interiores, las artes decorativas lo hicieron por medio de carteles, decoraciones de libros, encuadernaciones, etc. El modernismo busca construir una pequeña obra de arte en todos y cada uno de los objetos; de ese modo intenta unificar la forma ornamental y artística con el concepto de la utilidad.

Madera, hierro, vidrio y toda una gama de materiales se utilizan de modo magistral en la creación artesanal de muebles, vajillas, cerámicas, lámparas, faroles, vidrieras, instrumentos, cubiertos, rejerf́a, etc., en una búsqueda constante, apuntada ya por Carlo Argan, de continuidad estilística entre espacios interiores e exteriores.

Será, por tanto, lo ornamental, lo decorativo, lo que concrete al modernismo en su conjunto.

R. Schmutzler, en un reciente ensayo, define al modernismo como “... Aquel estilo que se desarrolló alrededor de 1900, cuyo leivmotiv era un largo y sensual movimiento" (9).

La imaginación como condición inexcusable, la mofologra: arabescos lineales y cromáticos; preferencias por los ritmos basados en las curvas y sus variantes (elipsis, voluta) y en el color por las tintas frías, tenues, trasparente el deseo de acortar la distancia existente entre las artes "mayores" (arquitectura, pintura, escultura) y las "aplicadas" en diversos campos; la búsqueda de funcionalidad decorativa; la aspiración a un estilo internacional o europeo; la temática naturalista (flores y animales); el empleo de motivos icónicos y estilísticos; el alejamiento de la proporción y el equilibrio; la búsqueda de ritmos "musicales" con marcadas evoluciones de al tura 0 anchura y con soluciones ondulantes y sinuosas; el evidente y constante propósito de comunicar un sentido de agilidad, elasticidad, ligereza, juventud y optimismo, son algunas de las muchas características que se identifican con este estilo de "fin-de-siècle" que, con un sentido romántico, rechazaba cualquier imposición de formas (10).

(9) SCHMUTZLER, R.: El Modernismo. Editorial Alianza, Alianza Forma, núm. 12, Madrid, 1980, pág. 9.

(10) Algunas de estas características han sido recogidas por Giulio Carlo Argan en obra citada., págs. 229 y 244. 
Extendido por diferentes pafses del occidente europeo, el modernismo contó pronto con gran número de obras creadas por maestros tan significativos como Víctor Horta, en Bélgica; August Endell, en Alemania, Héctor Grimard, en Francia; Henry Van de Valde, etc.

Los intercambios culturales que durante este período se llevaron a cabo fueron extremadamente abundantes. Los movimientos y artistas se alentaban recíprocamente de diferentes maneras, y esto permitio que el modernismo alcanzara una rápida difusión.

Este nuevo estilo hizo su aparición en Espafia o más bien en el área barcelonesa. Al parecer, referirse al modernismo arquitectónico en Espana supone hablar de un fenómeno de renovación estética asociado a una fuerte ideologia de carácter político, que nada tenia que ver con Art Nouveau ni los demás modernismos europeos: la exaltación catalanista, la Renaixença, y a una burguesía de base industrial, comercial, bancaria y, por tanto, adinerada.

Los más representativos arquitectos de este perfodo fueron Lluis Doménech Montaner, en quien hallamos el paso del eclecticismo al modernismo sin violencia (11), y Antoni Gaudí i Cornet, máximo exponente de la imaginación y calidad artística que el modernismo tuvo en España, situándolo a la altura de los existentes en otros países europeos.

Sería fatuo por nuestra parte intentar of recerles aqur un estudio, ni siquiera breve, sobre la vida y la obra gaudiana tan extensa y profundamente estudiada. Por tanto, recurrimos a las palabras de Schmutzler: "La concepción que Gaudí tenfa del edificio como una obra de arte total, fundida de una sola pieza; su predilección por la decoración fastuosa, los valores decorativos y simbólicos a un tiempo de sus construcciones y, finalmente, su mundo formal, que abarcó todos los campos de la vida vegetal y animal (en un sentido figurado, también en esto era eminentemente "católico"), hicieron de él un artista que tras sus formas a menudo atípicas, individualitas, realiz 6 las intenciones intimas del modernismo de manera grandio$\mathrm{sa}^{\prime \prime}$ (12).

Este modernismo catalán de Gaudí y otros, se proyectó en zonas inmediatas o lejanas, y obras afines y pertenecientes a este estilo irían apareciendo en diversas ciudades españolas, peninsulares (Valencia, La Coruña, Bilbao, Murcia...), insulares (Mallorca), o, como en nuestro caso, enclava-

(11) NAVASCUES y otros, en su obra citada, dice: "Cabe, incluso, adelantar que el llamado modernismo no es sino la manifestación final del eclecticismo." Con ello aclara este autor que el origen de la arquitectura de nuestro siglo y la ruptura con la del pasado no hay que buscarlos en el modernismo, sino en el llamado Movimiento Moderno. La contradicción ecntre electicismo y modernismo, según él, es sólo aparente.

(12) SCHMUTZLER, R.: Obra citada, pág. 146. 
das en el Norte de Africa (13).

Tales obras fueron realizadas por arquitectos catalanes que se desplazaron a los lugares donde hoy se encuentran, si bien, en otros casos, fueron arquitectos e ingenieros locales los que, siguiendo el ejemplo de estos portadores de la estética modernista, contribuyeron a la amplitud de este arte con particulares in terpretaciones.

\section{Enrique Nieto}

Y sería uno de aquellos arquitectos catalanes, Enrique Nieto y Nieto, quien, en junio de 1909, vendría y daría "carácter modernista a la ciudad de Melilla, mediante numerosos edificios" (14).

El único estudio que conocemos sobre la obra de Nieto en nuestra ciudad es el realizado por Salvador Tarragó Cid (15), prestigioso arquitecto integrado en las jóvenes generaciones de los años sesenta. Se trata de un breve estudio, tan solo de catorce páginas, en el que Tarragó esboza la personalidad de Nieto, of rece una interpretación crítica de su obra y abre, de este modo, una red de vías esclarecedoras sobre la arquitectura civil melillense de comienzos de siglo, ya sea en aquellas construcciones netamente modernistas, ya en otras de corte novecentista, racionalista, etc.

Por tanto, casi todos los datos que sobre la vida y obra de Nieto vamos a exponer a continuación han sido extrárdos de este estudio.

Enrique Nieto y Nicto nace en Barcelona en 1891. A los diecisiete años ingresa en la Escuela de Arquitectura y termina la carrera en 1906. Durante tres años trabaja en la ciudad Condal, participando en la realización de la Casa Milà, también conocida por "La Pedrera", construida entre 1905 y 1910, bajo la direcci ón de Gaudí.

No hay noticias de los motivos que impulsaron a Nieto a desplazarse a Melilla. Lo cierto es que en esta ciudad permaneceria hasta su muerte, en 1954 cuando contaba sesenta y tres años de edad.

A pesar de que Nieto llegó a Melilla con anterioridad a los sucesos de la Semana Trágica, no es estraño pensar que se sintiera atrafdo por esta ciudad norteafricana: por aquel entonces los acontecimientos políticos que se produjeron a raiz de la presencia de España en Marruecos unieron a Barcelona con el Norte de Africa.

(13) AGUILAR, Inmaculada: Demetri Ribes 1875-1921. Col. lecció 3i4, Valencia, 1980. GARCIA ANTON, Irene: La arquitectura de principios de siglo en Alicante y provincia. Excma. Diputación Provincial de Alicante, 1980. PEREZ ROJAS, Javier: Casinos de la región murciana. Un estudio preliminar. 1850.1920. Colegio Oficial de Arquitectos de Valencia y Murcia, Ferando Torres, editor, Valencia, 1980.

(14) Ars Hispaniae, vol. "Arquitectura Modernista fuera de Cataluña", pág. 41.

(15) Varios autores: Memoria de la Cátedra Gaudi. "Don Enrique Nieto y Nieto", por Salvador Tarragó Cid, pág. 21 a 34. Escuela Técnica Superior de Arquitectura. Ediciones Gea, Barcelona, 1970. 
Por otro lado, este mismo hecho influiría en la labor inicial de Nieto como arquitecto. La acción en Marruecos obligó al Gobierno español, regido por Maura, a movilizar tropas que arrastrarian una abundante población civil. Este crecimiento demográfico significó la realización de urbanizaciones de mayor envergadura sobre las improvisadas de los primeros asentamientos.

Siguiendo a Salvador Tarrago, podemos dividir la actividad profesional de Nieto en tres etapas: una de 1910 a 1931, en la que don Enrique construye las primeras casas con cuatro y cinco plantas. Son los edificios modernistas que se hallan enclavados en la zona centro de esta ciudad; la segunda etapa abarcó desde 1932 a 1939. Nieto consigue la plaza de Arquitecto Municipal, y desde su despacho desarrollará una fecunda labor constructora, en la que sintetizara corrientes de diversa indole, como novecentismo y racionalismo. Numerosos edificios con este carácter heterogéneo se extienden por toda la ciudad. La tercera y última etapa corresponde a la posguerra, entre los años 1940 y 1954 . Es el momento en el que se construyó el Palacio Municipal, su última gran obra arquitectónica, a caballo entre el novecentismo y el racionalismo.

Un largo paseo por Melilla llevará a la conclusión de que Nieto fue un arquitecto extremadamente fecundo. Tarragó asevera que "una tercera parte de la ciudad de Melilla es obra suya" (16).

La acción de Nieto provocó la formación de una escuela local de artesanos y de una serie de ingenieros militares que, al amparo de su influencia, llegaron a realizar en ocasiones edificios de gran calidad artística.

Nieto, aparece a los ojos de Tarragó como "técnico responsable de la formación de las nuevas ciudades industriales y coloniales, es un claro servidor de la clase social que protagoniza el momento histórico: la burguesfa... que es la única que le hace trabajar" (17).

En cuanto a la calidad de sus obras, de nuevo Tarragó afirma que mantiene un elevado término medio, y que "su obra registra este intento difícil de hacer construible, es decir, arquitectónico, lo heterogéneo, lo ambiguo, el mal gusto, la cursilerfa o la urbanidad encorsetada. Pero es precisamente en este quedarse a medio camino de todo en lo que reside su valor, en hacer de esta contrariedad arquitectónica una categorła artística" (18).

Realmente Nieto fue un artísta contradictorio, que, gradualmente, sin brusquedades, evolucionó de un "ismo" a otro, habiendo ensayado la mayoría de las tendencias arquitectónicas de su época.

(16) TARRAGO: Obra citada, pág. 28.

(17) Idem, obra citada, pág. 29.

(18) Idem, obra citada, pág. 33. 
Por último, reseñamos las palabras con las que Tarragó cierra su breve estudio; con ellas establece, como en otras ocasiones una correlación entre la figura de Gaudí y la de Nieto, y dice: "Nieto creo que fue el único de sus colaboradores que comprendió o intuyó la problemática del maestro, y aunque no llegó a desarrollarla a la misma altura, al menos ensanchó el campo de experiencias a otros órdenes nuevos" (19). Con esto nos da a entender que Nieto no se encuentra entre aquellos seguidores de Gaudr que se limitaron a plagiarlo, sino entre los pocos elegidos que supieron interpretar verazmente el mundo gaudiano.

\section{EL MODERNISMO DE MELILLA}

\section{Breves notas acerca del ensanche de la ciudad}

Antes de adentrarnos en el arte modernista que Enrique Nieto hiciera surgir en la ciudad de Melilla y que iba a configurar a ésta un carácter peculiar, es necesario comunicar al lector algunas breves notas históricas y urbanísticas.

Melilla, tierra española desde 1497, contaba en los albores del siglo XX, momento de la expansión de Art Nouveau en España, con una población censada de 8.956 habitantes, que residfan casi en su totalidad en la antigua acrópolis, conocida hoy como "Melilla la Vieja", ubicada ésta en un pequeño promontorio cuyos cimientos datan de la época de la conquista. Es el momento en que va a comenzar la expansión de la ciudad, expansión que, con el correr del tiempo, abarcará toda la zona céntrica y barrios del territorio melillense. Este crecimiento urbanístico irá acompañado de un crecimiento demográfico; así en 1949, año en que se jubila Eduardo Nieto, la población será de 95.841 habitantes.

A causa de una serie de peculiaridades existentes en torno a Melilla, como son su situación geográfica, su carácter militar y comercial, sus fronteras y el ser ciudad de ultramar, el crecimiento de la ciudad se va a ver condicionado e influenciado por todos los componentes sociales y económicos que la conforman.

La construcción del primer barrio de Melilla, fuera del recinto amurallado comienza en el año 1888 y se trata del Polígono Excepcional de Tiro, nombre debido a que éste era hasta entonces el Campo de Tiro, que tenf́a la guarnición de Melilla. En 1891 se habran construido ya en él cuatro manzanas de casas. Este barrio, pionero de la ciudad, nos sirve para ejemplificar lo que casi será una constante en la edificación de los extrarradios de Melilla: el carácter militar, en principio, de éstos.

(19) Idem, obra citada, pág. 34. 
En efecto, la mayoría de los barrios comenzaron siendo zonas de asentamientos de tiendas de campaña, campamentos montados con distintas finalidades, que iban evolucionando y agrupando en torno a sí a un número de personal civil que sobreviv ́an al amparo de las necesidades derivadas de la vida militar. Iban surgiendo chabolas y cuevas que se convertian en pequeñas habitaciones o viviendas. La iniciativa de edificación era, usualmente, debida al general de la Plaza. A estos generales se debe una gran parte de la primitiva urbanización y construcción de la ciudad moderna, as ́ como a los ingenieros militares.

Como norma, y siempre con excepciones, podemos afirmar que los barrios más antiguos estaban configurados e iniciada su edificación entre los años 1895 y 1910. Se concedió permiso para levantar pisos sobre las viviendas de planta baja, en el Plan de Urbanización de 1910, un ano después de la llegada de Nieto a Melilla; a pesar de ello muchas casas continuaron sin levantar pisos superiores hasta transcurrido casi el primer cuarto de siglo.

\section{Carasterísticas y aspectos del modernismo en Melilla}

El carácter de la ciudad y el que Melilla sea un "verdadero museo de arquitectura de estilo modernista, sólo superado por Barcelona" (20), se debe, a pesar de que esta ciudad generalmente no ha sido incluida entre las variantes regionales del modernismo (21), a la ya citada y comentada figura de Enrique Nieto.

Nieto, al realizar una exhaustiva labor iba a dejar su huella en todos los rincones de la ciudad, siendo esto una de las características principales del modernismo en Melilla.

En Melilla el sentir modernista no se limita a una calle o avenida, arteria de la zona centro, sino que se hace presente en casi todos los lugares de la ciudad que fueron edificados entre 1909 y 1949, con una presunta independecia estilística -si bien no económica, ya que en Melilla, como en otros lugares, las edificaciones de la zona céntrica responden en su mayor a a la clase burguesa - de la zona de edificación.

La condición geográfica de Melilla, y el hecho de estar alejada de los principales focos del arte y la cultura europeas va a condicionar, en cierto modo, las posibilidades artísticas de la ciudad. $\mathrm{Si}$, ciertamente, las ideas modenistas arraigaron en Melilla durante los afios de apogeo de este movimiento artístico en Barcelona y otras ciudades, en Melilla pervivirá durante un largo periodo, con las fusiones, variaciones y transformaciones propias de todo arte.

(20) DOMINGUEZ, Constantino: Melllla, pág. 23, Editorial Everest, León, 1978.

(21) Historia del Arte Hispd́nico. Vol. 5. "Del neoclasicismo al modernismo". P. Navascues, C. Pérez, A. M. ${ }^{\mathrm{a}}$ Arias de Cossío. Ed. Alhambra, Madrid, 1979. 
La Escuela de Arquitectos y Artesanos surgida en torno a Enrique Nieto va a estar condicionada por la evolución de éste, ya que no se puede hablar en esta ciudad de una excesiva afluencia, al menos en la primera mitad del siglo $\mathrm{XX}$, de ideas artísticas.

El modernismo nace en Melilla sin que en ella exista un pasado, ni una tradición artística, pues la ciudad no contaba con la experiencia arquitectónica del neoclasicismo ni de ninguna otra tendencia o ideologla artística, exceptuando una pequeña muestra gotica en la ciudad antigua, de fines del siglo XV o principios del XVI (22), y pervive alejada de las exposiciones y ublicaciones que contribuian al enriquecimiento del género. Recordemos que "ningún otro movimiento artístico del siglo $\mathrm{XX}$ ha organizado tantas exposiciones, contemplándose a sí mismo y ofreciéndose a la admiración" (23).

Del mismo modo, el enclave africano de Melilla y su limitada extensión iban a condicionar la posible riqueza del arte modernista melillense en otros aspectos.

Al no contar la ciudad con ninguna cantera explotada, se ve limitada en su creación y elaboración artística a los materiales existentes y fabricados en ella (asperón, ladrillo...), o bien a aquellos cuya importación no resultase excesivamente dificultosa ni costosa (madera, hierro). Es de notar que una ciudad con abundantes muestras de sensibilidad modernista en diversos órdenes (arquitectura, forja, mobiliario, etc.) apenas conserve piezas $u$ objetos cultivados con esmero por este arte (cerámica, vidrio, etc.).

En cuanto a las artesanias, artes aplicadas y artes decorativas se refiere, existen en Melilla numerosos trabajos, realizados en distintos materiales, cuya ornamentación, originalidad y fantasía constituyen un claro exponente de la huella modernista.

El hierro forjado, usado en principio como protesta ante la industria del hierro fundido, es utilizado en fallebas, tiradores, rejas, cerraduras artisticas, albadones, barandillas, escaleras, elevamuebles y demás objetos de los que existen abundantes muestras en las calles José Antonio Primo de Rivera, Cándido Lobera, López Moreno, Cardenal Cisneros y otras, objetos que estuvieron realizados, en su mayoría, en los talleres de fundición de la Compaña Hispano-Marroquí de Gas y Electricidad o en la Compañ fa Velasco.

Algunas de estas muestras en forja debieron responder también a patrones artísticos utilizados en otros lugares. Curiosamente hemos encontrado, en la calle López Moreno de Melilla, una réplica de las rejerras utilizadas en

(22) Véase "Un gótico en Africa", de Miguel Fernández. Tomado del A. B. C. de Madrid, y recogido en la revista Prensa.3, núm. 3, Melilla, 1982. 1980.

(23) SCHMUTZLER, R.: El Modemismo, pág. 16. Alianza Forma. Alianza Editorial, Madrid, 
balcones de viviendas de la ciudad de Vigo (24).

Gran importancia tuvieron también en el arte que nos ocupa las artes gráficas, éstas no sólo se ven impulsadas a través de libros, sino también por medio de carteles, prospectos de propaganda, rotulaciones de periódicos y todo el vasto campo en el que por medio de grabados, colores y tintas contribuyen en gran medida a la difusión de las ideas modernistas. Walter Crane, discípulo de Morris, fue el iniciador del renacimiento de las artes del libro. "El libro no sólo debra ser bello, sin ante todo legible, sus paginas debían ser claras y fáciles de leer, el tipo de letra bien dibujado y el margen apropiado a las dimensiones de las páginas..." (25). En Melilla se imprimieron, en los talleres de El Telegrama del Rif y Gráficas Melillense, en esos años varios libros, de los cuales algunos tenfán en la portada la huella del sentir modernista, sentir coman a la ciudad en ese tiempo. Sin embargo las artes gráficas tuvieron en esa ciudad mayor difusión en otros campos, tales como carteles de cine y revistas.

Menos numerosos son los ejemplos existentes en cerámica, material de fácil deterioro, utilizado en Melilla con frecuencia en las partes superiores de las fachadas, en remates de cúpulas y pináculos... En la actualidad se conservan algunas cúpulas, como las del Palacio Municipal o las gallonadas de la Casa de la Reconquista, los frisos existentes en la parte superior de las fachadas de la calle Cardenal Cisneros, Gabriel de Morales y otras. Se han perdido, a causa del tiempo y el abandono muestras en cerámica y azulejos de semblanza gaudiana, como las de la calle José Antonio Primo de Rivera, número 13.

Por lo que respecta al vidrio, no hubo en Melilla, o si lo hubo no existen datos de ello, artesanos que trabajasen en la elaboración de vasos policroma dos, jarrones, estatuillas $u$ otro tipo de objetos propios del arte que nos ocupa elaborados a partir de vidrio soplado, por lo que las muestras existentes en la citada ciudad provienen de importaciones. Debieron existir posiblemente vidrieros que trabajaron con esmero y calidad en el desarrollo de algunas vidrieras, si bien es cierto que llegaron a encargarse éstas en ocasiones a diversos lugares. Se conservan importantes muestras de vidrieras plomadas en la calle General Pareja, núm. 10. Pudieron existir muchas más, ya que fueron propias de tiendas y almacenes, y Melilla es una ciudad eminentemente comercial, pero se han deteriorado o perdido con el paso del tiempo.

Las artes decorativas, centro de atención del modernismo tuvieron un ámbito importantísimo dentro del mundo del comercio a través de anun-

(24) S. IGLESIAS, Lena; GARRIDO, Xaime: Vigo. Arquitectura Modernista 1900-1920, pág. 38. Publicacion do Colexio Oficial de Arquitectos de Galicia, Vigo, 1980.

(25) LITVAK, Lily: Transformación industrial y literatura en Espafia (1895-1905), pág. 23. Taurus Ediciones, Madrid, 1980. 
cios, carteles, escaparates. Sterner (26) habla del encanto de los escaparates -en el modernismo aparecen los primeros escaparates propiamente dichos-y de cómo éste surge del contraste entre la gran superficie plana del cristal con el encuadre o marco de tres dimensiones. Finalmente, muchos establecimientos acomodaron su ornato al gusto de la época. Madera, yeso y cristal se combinan a través de mostradores con bajorrelieves a base de dinámicos movimientos ondulantes, que en ocasiones se repetían por paredes $y$, a veces, techos.

El comercio de Melilla, en el que las artes decorativas se mantienen en su más pura esencia es, actualmente "Cafés El Gurugú", en la calle General Pareja, 10; asimismo, la Farmacia Romero, sita en Ejército Español, 7, conserva aún el encanto modernista.

Fueron muchísimos los locales comerciales de esta ciudad en los que el modernismo arraigó con fuerza, sin embargo, lamentablemente, y debido a renovaciones, obras o reparaciones, en la actualidad son muy pocos los que conservan el sabor de principios de siglo.

Las artes decorativas en Melilla han soportado mal el paso del tiempo. Han sido numerosos los locales y edificios públicos que, nacidos en el más puro y artístico modernismo, han sufrido los cambios más despiadados, perdiéndose toda la riqueza ornamental de sus interiores, en un esfuerzo por adaptarse a tiempos y formas más nuevas.

Buenos exponentes de lo dicho son el Banco Central, hoy irreconocible; el Cine Nacional y el Cine Monumental.

Sin embargo, se conservan todavía algunos interiores en los que se contempla una profusa decoración y ornamentación modernista. Tales son una buena parte de los interiores del Casino Español, en la Avenida Generalisimo, 12. Sabido es que la construcción de casinos fue tratada con especial celo por el arte modernista.

Numerosos y destacables fueron también los trabajos realizados en Melilla por ebanistas y artesanos de la madera, que dejaron su talento y creatividad no sólo en muebles, sino también en interiores de escaleras y en puertas.

Barandillas y pasamanos que cobran movilidad a través del predominio de formas ondulantes, con la representación de líneas, curvas o feroces animales en sus remates. Son muchos los pasamanos de escaleras que comienzan en forma de rostros, leones, peces o simplemente hojas y flores.

Claro y magnifico exponente de este trabajo artesanal son las puertas $\mathrm{y}$ portones exteriores e interiores en las que la imaginación y el arte se conjugan, perdiendo su carácter de "añadido" para tender a conformar el pro" pio objeto. La ormentación hace hermosa a la funcionalidad.

(26) STERNER, Gabriele: Modernismos, pág. 66. Ed. Labor, Barcelona, 1977. 
En perfecta armonfa con las sinuosas formas interiores de techos, escaleras, puertas, se alzan majestuosas variadas formas exteriores pertenecientes a fachadas de edificios, casas en las que el peculiar sentido del Art Nouveau, iba a conferir a la ciudad lo que se ha dado en llamar cierto aire de belleza y modernismo.

Con las posibilidades ya aludidas, con un material poco noble en ocasiones (como es el caso del asperón), iba a surgir en Melilla una prodigiosa y profusa riqueza ornamental de la que son buenos exponentes una gran parte de las fachadas melillenses.

El abundante mundo de la vegetación y la flora que el modernismo cultivaba se hace presente a través de hojas de acanto, de flores diversas, de palmeras, que perviven en aristas de las fachadas; un repertorio floral situado junto a terrados $y$ azoteas, o un buen número, más de veinte modelos diferentes, de sobreventanas.

Al lado del reino vegetal y en perfecta armonfa con éste existe el reino animal, pudiendo encontrarse desde majestuosas águilas en vuelo, elefantes $o$ peces a un sin fin de leones o animales afines, entre los que se cuentan más de seis modelos diferentes, a modo de ménsulas, en sobrepuertas, coronando las sobreventanas o formando parte de balaustradas.

No es de extrañar la aparición de este "bestiario" en la ornamentación de los edificios de Melilla, pues sabido es que el modernismo cultiva la temática naturalista, sobre todo a través de flores y animales. Sin embargo, sí podemos apuntar que, a pesar de la gran variedad de especies animales encontradas, no se han hallado muestras ornamentales de aquellos dos animales que de modo preferente trató el arte modernista: el cisne y el pavo real.

Otro aspecto ornamental, además de lazos, guirnaldas, medallones, balaustradas y los ya comentados, es el tratamiento del rostro y la figura humana, aspectos ambos no demasiado frecuentes, en lo que a ornamentación de fachadas se refiere, en el más puro modernismo gaudiano, pero s 1 cultivado por otros muchos arquitectos, entre los cuales está Enrique Nieto.

Este tipo de ornamento está presente, casi como una costante, en la mayoría de las edificaciones melillenses nacidas dentro de este sentir. Si bien la figura humana completa está ausente en las fachadas de esta ciudad, es muy frecuente encontrar rostros que, a menudo, coronan ventanas o puertas, o bien están formando parte de ménsulas, o situados en las partes centrales y superiores de diversas fachadas. A veces son rostros con apariencia infantil y más frecuentemente, cabezas femeninas ataviadas con tocados de lazos y flores que encierran dentro de sí toda una simbología utilizada por el modernismo (27) y que, no obstante, evocan diversas épocas o estilos.

(27) Véase la obra de STERNER, obra citada, pág. 18, donde se trata del lenguaje simbólico de las flores, desarrollado por el Art Nouveau. 
Son varios los moldes utilizados en Melilla, y es mucho más usual el tratamiento de rostros femeninos que masculinos, ya que éstos aparecen, únicamente, en cuatro o cinco ocasiones, y no en aquellas casas en las que la ornamentación modernista alcanzara sus más altas cotas. En las mejores edificaciones dentro de este estilo, propias de la clase adinerada y, por tanto, de la zona céntrica, son los rostros de mujer, o los que podŕamos llamar asexuados con rasgos angelicales, los únicos que aparecen. Para finalizar, anotamos que estas caras son tratadas casi siempre en planos "de frente" y sólo en una ocasión encontramos rostros "de perfil" (se trata de tres caras iguales dos en sobreventanas y una en sobrepuerta, en la calle Fernández Cuevas). Los caracteres de las caras que encontramos suele responder, en general, a rasgos de niños o personas de mediana edad; nunca se trata la figura del viejo (los rostros masculinos con barbas sí son frecuentes en otras ciudades.

Todo ello pervive, en fachadas pintadas, al menos genuinamente, en tonos ocres y blancos (28), como rasgo ornamental de signo modernista.

Sin embargo, y dentro de criterios de estilo es peligroso e incierto el intentar agrupar a un gran número de edificios bajo el título de "modernistas", "racionalistas", o "historicistas", ya que éstos aparecen mezclados $y$, en ocasiones, confundidos, como ya apuntaba Tarragó haciendo referencia a Enrique Nieto.

"La versatilidad que ofrecen muchas de sus obras al no corresponderse cronológicamente con una cierta línea evolutiva, al dejarse influenciar por edificios locales o foráneos, que a veces contradicen sus propias tendencias expresivas, junto a la presencia de otros muchos factores (asf, por ejemplo, por un lado el gran número de sus edificios y reproducciones de sus seguidores, producen las más extremas verificaciones de mixtificación; as 1 casas con la planta baja modernista, dos plantas encima novecentista y las últimas racionalistas cuando no otras mezcolanzas más extremas de los elementos arquitectónicos de estilos distintos extrañamente barajados, son situaciones muy normales; por otro lado, el ser Melilla un cruce de civilizaciones tan contrapuestas como son la europea y la árabe, se producen las consiguientes influencias y mezclas con la desambientación muy frecuente de los elementos de cada cultura arquitectónica), of recen situaciones a veces paradójicas y contradictorias que hacen dif́cil una comprensión de todo el proceso seguido por Nieto.

...Entonces surgen obras de todos los estilos y maneras modernistas, modernistas-racionalistas, novecentitas, novecentistas-racionalistas, racionalitas, racionalistas-monumentalistas, monumentalistas, y después todas sus

(28) Véase artículo: "Se precisa más colaboración entre los propietarios de edificios de interés histórico-artístico y las autoridades." De Luciano Tejedor, en el períodico El Telegrama, de Melilla, 13 de Mayo, 1982, pág. 6. 
combinaciones posibles, etc." (29).

Consideramos que esta situación de fusión y confusión, lejos de ser caótica, bien puede constituir una de las bases, o de las últimas características de esta estética melillense en su faceta ornamental, agrupada común, y muchas veces, erróneamente, bajo la denominación de "modernista", debido a esto último, a no ser el modernismo el único estilo artístico-arquitectónico, pero sí el primero y más representativo, a que su arraigo en Melilla se debe a un hombre Enrique Nieto, de formación modernista, que irfa evolucionando posteriormente a otras tendencias.

A modo de resumen, tras este breve análisis del sentir modernista en Melilla y tras haber comentado aquellos rasgos o aspectos que nos han parecido más significativos, concluimos abogando por la rica existencia de un arte nacido dentro de la estética modernista y que, superando una serie de dificultades, arraigó y se desarrolló en Melilla en la primera mitad del Siglo XX. Ello, favorecido, tal vez, por la luminosidad de la ciudad, hace de Melilla uno de los lugares más hermosos y representantivos de la Espana modernista.

"El ámbito modernista de Melilla", parte de un trabajo, en realización, más amplio, con base fotográfica, quiere ser una $\mathrm{kOz}$ más de esperanza en la recuperación artística de la ciudad, y sumarse, humildemente, a la labor de sensibilización que en torno a los temas relacionados con el arte modernista viene desarrollando la Dirección Provincial de Cultura, el Excmo. Ayuntamiento de Melilla y todas aquellas personas que aman las peculiaridades artísticas de esta ciudad espanola en el Norte de Africa.

Es de esperar que esta empresa en la que con tanto interés se está trabajando desde la Administración local, así como desde la iniciativa privada, logre su éxito, y no sólo no se pierdan más edificios de interés histórico-artístico, si no que se restauren aquellos próximos a desaparecer.

Por último, señalar que no ha sido, en ningún momento, nuestra intención abordar la Historia del Arte o de la Arquitectura, y sí lo ha sido contribuir a la divulgación de la existencia de una determinada corriente artística de principios de siglo que adquirió un peculiar desarrollo en $\mathrm{Me}$ lilla, pasando a formar parte para siempre de su belleza.

(29) TARRAGO CID, Salvador: Obra citada, pág. 30-32. 